\title{
pÿMen s age at first birth and alcohol-related morbidity and mortality among siblings
}

\section{Einiö, Elina}

2020-04-01

pÿEiniö , E , Hiltunen , E , Martikainen , P \& Korhonen , K 2020 , ' Men s age at first birth and alcohol-related morbidity and mortality among siblings ' , Drug and Alcohol Dependence , vol. 209 , 107942 . https://doi.org/10.1016/j.drugalcdep.2020.107942

http://hdl.handle.net/10138/327186

https://doi.org/10.1016/j.drugalcdep.2020.107942

cc_by_nc_nd

acceptedVersion

Downloaded from Helda, University of Helsinki institutional repository.

This is an electronic reprint of the original article.

This reprint may differ from the original in pagination and typographic detail.

Please cite the original version. 


\section{Men's age at first birth and alcohol-related morbidity and mortality among siblings}

Elina Einiö $^{\mathrm{a}, \mathrm{b}}$, Elina Hiltunen ${ }^{\mathrm{a}}$, Pekka Martikainen ${ }^{\mathrm{a}, \mathrm{c}}$, Kaarina Korhonen ${ }^{\mathrm{a}}$

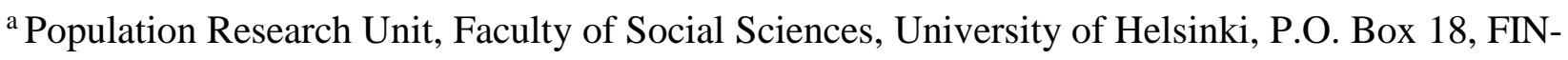
00014 Helsinki, Finland

${ }^{\mathrm{b}}$ London School of Economics and Political Science, Department of Social Policy, London WC2A 2AE, United Kingdom

${ }^{c}$ Department of Public Health Sciences, Stockholm University, Stockholm, Sweden

Correspondence to: Elina Einiö, Population Research Unit, Faculty of Social Sciences, University of Helsinki, P.O. Box 18, 00014, Finland, tel: +358 50 3199368, e-mail: elina.einio@ helsinki.fi 


\title{
Men's age at first birth and alcohol-related morbidity and mortality among siblings
}

\begin{abstract}
Background: Men's age at first birth may negatively or positively affect alcohol-related morbidity and mortality, although little evidence is available. Methods: We used register data of over 22,000 brothers to analyze the associations between age at first birth and alcohol-related morbidity and mortality from the age of 35 until the age of 60 or 72 . We employed conventional Cox models and inter-sibling models, which allowed adjustment for unobserved social and genetic characteristics shared by brothers. Results: The findings show that men's age at first birth was inversely associated with alcohol-related morbidity and mortality, independent of unobserved characteristics shared by brothers and of observed demographic confounders. Men who had their first child late at 35-45 years experienced lower alcohol-related morbidity and mortality $($ hazard ratio $(\mathrm{HR})=0.57,95 \%$ confidence interval $(\mathrm{CI})=0.43,0.75)$ than men who had their first child at 25-29. Men who had their first child before age 20 had the highest morbidity and mortality among all fathers $(\mathrm{HR}=1.36,95 \% \mathrm{CI}=1.09,1.69)$, followed by men who had their child at 20-24 $(\mathrm{HR}=1.12,95 \% \mathrm{CI}=1.00,1.25)$. Conclusions: The results imply that the inverse association between men's age at first birth and alcohol-related morbidity and mortality is not driven by familial characteristics.
\end{abstract}




\section{Introduction}

Previous studies indicate that the age at entry into parenthood affects the later-life health of parents (Barclay et al., 2016; Einio et al., 2015; Einio et al., 2019; Grundy, 2009; Henretta, 2007). When persons are older at entry into motherhood or fatherhood, they have had more time to gather the social and economic resources needed to cope with the stresses related to parenthood, which could improve their later-life health. However, little empirical evidence exists on the use of alcohol and on alcohol-related morbidity based on men's reproductive behavior. Yet, several mechanisms linking age at first birth and alcohol use have been suggested. The stress proliferation theory argues that relatively early parenthood is causally related to increases in alcohol use, whereas the role incompatibility theory suggests that early parenthood is associated with a decrease in alcohol use, because the responsibilities of parenthood inhibit or interfere with binge drinking already earlier in life (Wolfe, 2009).

To our knowledge, only one earlier study has analyzed men's age at first birth and alcoholrelated mortality (Grundy and Kravdal, 2010). This Norwegian study indicated that age at first birth was associated with mortality, with young first-time fathers having the highest alcoholrelated mortality and older fathers the lowest. However, causal inference from these observational data is difficult due to the confounding influences of omitted variables. The association between the timing of parenthood and alcohol-related mortality is possibly spurious in the sense that both are determined by the same characteristics, such as childhood background, intergenerational norms of behavior, cognitive ability, and genetic characteristics. For instance, early fatherhood has been linked with a disadvantaged socioeconomic background (Bamishigbin

et al., 2019; Hynes et al., 2008; Kiernan, 1997; Michael and Tuma, 1985), risky behaviors (Bamishigbin et al., 2019; Lehti et al., 2012), and low cognitive ability (Einio et al., 2019), all of which could increase the use of alcohol and alcohol-related morbidity (Maggs et al., 2008; 
Pensola and Valkonen, 2002; Sjolund et al., 2011; Sjolund et al., 2015). An inter-sibling approach reduces the bias caused by the confounding influences of social and genetic characteristics that siblings share (Barclay et al., 2016; Einio et al., 2015; Lahey and D'Onofrio, 2010). Siblings are also more likely to share peers than individuals randomly selected from a population, and peer influence is known to play an important role in explaining risky behavior during adolescence (Gardner and Steinberg, 2005). However, there are currently no inter-sibling analyses available about the relationship between men's ages at first birth and alcohol-related morbidity or mortality.

The present study examines the association between men's age at first birth and alcoholrelated morbidity and mortality, using both an inter-sibling approach and a standard approach conventionally used among unrelated individuals. We compare the results from these models in order to assess whether the association is confounded by the influences of social and genetic characteristics common to brothers.

\section{Methods}

\subsection{Study population}

We based these analyses on a $10 \%$ household sample drawn from the 1950 Finnish census combined with mortality and hospitalization follow-up data available from 1971 to 2010. Statistics Finland linked the sample to demographic information from 1970, 1975 and 1985 censuses and to almost complete information on the age at which individuals become a parent for cohorts born after 1938 (Einio et al., 2016).

Our sibling analysis comprised 22,132 brothers born between 1938 and 1950 who had not emigrated or died before the age of 35 . These study subjects had at least one brother with whom they had shared a family home in 1950 at $0-12$ years. Brothers who had lost both parents in 
childhood could not be linked because sibling linkage was carried out through a living parent. Our conventional cohort analysis included 43,550 men born between 1938 and 1950.

\subsection{Exposure}

Statistics Finland provided the month-level information on the birth of the study subject and their first child. These dates were set to the 15 th day of the corresponding month and year, and used to calculate the age at first birth. We categorized the age at the birth of a first child into five groups: under 20 years, 20-24, 25-29, 30-34, 35-45, and no children. In statistical analyses, the reference category comprised those who had their first child at standard ages 25-29.

\subsection{Outcome}

We utilized the national registry of inpatient hospitalizations (1973-2010) and the national registry of causes of death (1973-2010) to construct the outcome for alcohol-related morbidity and mortality from 35 years of age. Cause of death data were based on the International Classification of Diseases and Related Health Problems (ICD), synchronized by Statistics Finland. Information on hospital admissions and related diagnoses were based on register-based data provided by the National Institute for Health and Welfare, which uses the Finnish ICD, versions 8, 9 and 10 (ICD-8, ICD-9 and ICD-10).

We categorized study subjects as experiencing alcohol-related mortality or morbidity if their cause of death was attributed to alcohol-related diseases or alcohol poisoning (ICD-8: 291, 303, 5710, 577, E860; ICD-9: 291, 303, 3050, 3575, 4255, 5353, 5710-5713, 5770D-5770F, 5771C5771D, 7607A, 7796A, E851; ICD-10: F10, G312, G4051, G621, G721, I426, K292, K70, K860, K8600, 0354, P043, X45) or if their hospital admissions were attributed to alcohol (Laakintohallitus, 1969; Laakintohallitus, 1986; Stakes, 1999; Statistics Finland, 2003). We used 
the underlying cause of death, the primary cause of hospitalization and up to three contributory causes of hospitalization to assess alcohol-related morbidity and mortality. The outcome captures alcohol-related problems that are relatively severe. Supplementary Table 1 summarizes the hospital diagnoses used in our analyses.

\subsection{Statistical analyses}

We set the morbidity and mortality follow-up period as starting at age 35 (in 1973-1985 depending on the year of birth) and ending in December 2010, the time at which those included were 60 to 72 years old. The follow-up period began during the month subjects turned 35 and ended at the time of an alcohol-related hospitalization, alcohol-related death, other death, emigration or the end of the follow-up period, whichever occurred first. We modeled the risk of alcohol-related morbidity and mortality using both conventional Cox models and inter-sibling Cox models (Allison, 2009). The latter allowed us to adjust for the confounding influences of social and genetic characteristics brothers share.

Age at first birth was considered as a time-varying covariate. The year of birth, the level of education, and marital status were used as time-invariant covariates. We adjusted for the year of birth because of its link to fertility behavior and alcohol-related morbidity (Andersson et al., 2009; Valkonen and Kauppinen, 2005), and adjusted for education for similar reasons (Kravdal and Rindfuss, 2008; Nisen et al., 2014; Sondergaard et al., 2015). We grouped the level of education into three groups: basic or less, secondary and tertiary. The level of education and marital status were measured at ages 30-34 years. 


\section{Results}

Table 1 shows the adjusted hazard ratios (HRs) of alcohol-related morbidity and mortality based on conventional cohort analyses and inter-sibling analyses. The results from the cohort analyses show that the age at first birth was inversely associated with alcohol-related morbidity and mortality among men, independent of birth year, education, and marital status. Men who had their first child late, at ages 35-45, had the lowest alcohol-related morbidity and mortality $[\mathrm{HR}=$ $0.53,95 \%$ confidence interval $(\mathrm{CI})=0.44-0.64]$, followed by men who had their first child at ages $30-34(\mathrm{HR}=0.80,95 \% \mathrm{CI}=0.70-0.91)$, when compared to men who had their first child at ages 25-29 (the reference group). Furthermore, men who had their first child before age 20 exhibited the highest alcohol-related morbidity and mortality among all fathers ( $\mathrm{HR}=1.55,95 \%$ $\mathrm{CI}=1.33-1.81)$, followed by men who had their first child at ages $20-24(\mathrm{HR}=1.23,95 \% \mathrm{CI}=$ 1.14-1.33). In addition, men who had no children experienced an elevated risk of alcohol-related morbidity and mortality $(\mathrm{HR}=1.33,95 \% \mathrm{CI}=1.18-1.49)$.

The association between age at first birth and alcohol-related morbidity and mortality attenuated only modestly in the inter-sibling analysis. Our findings clearly show that men who had their first child at ages 35-45 exhibited a lower $(\mathrm{HR}=0.57,95 \% \mathrm{CI}=0.43-0.75)$ and those who had their first child at ages $20-24(\mathrm{HR}=1.12,95 \% \mathrm{CI}=1.00-1.25)$ or by age $20(\mathrm{HR}=$ $1.36,95 \% \mathrm{CI}=1.09-1.69)$ exhibited a higher alcohol-related morbidity and mortality than their brothers who had their first child at ages 25-29. Childless men had higher morbidity and mortality than their brothers in the reference group.

\section{Discussion}

In a first study of its kind, we show that age at first birth is inversely associated with men's alcohol-related morbidity and mortality, independent of the confounding influences of social and 
genetic characteristics common to brothers and of education and birth year. Our findings show that men who had their first child late at 35-45 years carried a diminished risk of alcohol-related morbidity and mortality, while men who had their first child before age 20 or at ages $20-24$ had an elevated risk compared with their brothers who had a first child at 25-29 years. These findings indicate that the association between men's age at first birth and alcohol-related harms does not result from the confounding influences of family characteristics. Thus, these findings strongly support the stress proliferation explanation (Wolfe, 2009), which suggests that becoming a father at a relatively young age could increase the use of alcohol as a coping mechanism for stress. Older fathers may have had more time to secure the human and social resources needed for parenting and, therefore, may cope better with fatherhood-related stresses. This interpretation is in line with the findings observed for alcohol-related mortality at the population-level in Norway (Grundy and Kravdal, 2010). Our findings indicate that men with no children have an increased risk of alcohol-related harm. Childless men might have fewer incentives to avoid healthdamaging behavior or to seek treatment for addiction. This interpretation is in line with previous findings observed for men (Einio et al., 2016; Grundy and Kravdal, 2010).

The main strengths of this study lie in the inter-sibling approach and the follow-up data spanning 60 years (1950 to 2010). Furthermore, Finnish national records on parenthood are internationally unique since they include information on age at first birth among men, a rare information in research on reproductive behavior. The sibling approach is of major importance, given that the relationship between age at first birth and alcohol-related morbidity observed at the population level could be biased by omitted genetic and social characteristics that affect both reproductive behavior and health. The sibling approach aims to reduce this residual confounding from factors shared by brothers, although not directly observed. These characteristics include risky attitudes towards alcohol use and reproductive behavior, genetic similarities, parental 
monitoring and social capital in childhood and adolescence. Of course, siblings can experience different situations within the same family of origin and they can be rather different from another. The main limitation of the inter-sibling analysis is that it does not account for unobserved factors not shared by siblings. Yet, siblings are nevertheless more alike than individuals randomly selected from a population, a factor that reduces the estimation bias resulting from omitted variables.

We must also note other limitations to our study. First, our analyses focused only on men since alcohol-related morbidity and mortality remained relatively rare in women, and therefore the data on sisters did not allow estimating the association with sufficient accuracy. Second, we could not identify whether brothers were biologically full or half brothers since the details of their biological links were unavailable in these datasets. Information on identical twins was also unavailable. Yet, this is the first study to show that the inverse association between men's age at first birth and alcohol-related morbidity and mortality is independent of unobserved social and genetic characteristics common to brothers and of observed demographic confounders.

In summary, the findings show that the lower alcohol-related morbidity and mortality observed among older fathers and the higher morbidity and mortality observed among young fathers are not driven by the confounding influences of familial characteristics. It is therefore likely that older age at fatherhood buffers the stresses related to parenthood and reduce fathers' alcohol-related morbidity. These findings are of policy importance because men's age at first birth has increased in recent years (Nilsen et al., 2013; Paavilainen et al., 2016). 


\section{References}

Allison, P.D., 2009. Fixed Effects Regression Models. Series: Quantitative Applications in the Social Sciences: Nro 160. Sage Publications, Thousand Oaks, California.

Andersson, G., Ronsen, M., Knudsen, L.B., Lappegard, T., Neyer, G., Skrede, K., Teschner, K., Vikat, A., 2009. Cohort fertility patterns in the Nordic countries. Demogr. Res. 20, 333352.

Bamishigbin, O.N.,Jr, Dunkel Schetter, C., Stanton, A.L., 2019. The antecedents and consequences of adolescent fatherhood: A systematic review. Soc. Sci. Med. 232, 106119.

Barclay, K., Keenan, K., Grundy, E., Kolk, M., Myrskyla, M., 2016. Reproductive history and post-reproductive mortality: A sibling comparison analysis using Swedish register data. Soc. Sci. Med. 155, 82-92.

Einio, E., Goisis, A., Myrskyla, M., 2019. Is the relationship between men's age at first birth and midlife health changing? Evidence from two British cohorts. SSM Popul. Health. 8, 100458.

Einio, E., Nisen, J., Martikainen, P., 2015. Is young fatherhood causally related to midlife mortality? A sibling fixed-effect study in Finland. J. Epidemiol. Community Health. 69, 1077-1082.

Einio, E., Nisen, J., Martikainen, P., 2016. Number of children and later-life mortality among Finns born 1938-50. Popul. Stud. (Camb). 70, 217-238.

Gardner, M., Steinberg, L., 2005. Peer influence on risk taking, risk preference, and risky decision making in adolescence and adulthood: an experimental study. Dev. Psychol. 41, 625-635. 
Grundy, E., 2009. Women's fertility and mortality in late mid life: A comparison of three contemporary populations. Am. J. Hum. Biol. 21, 541-547.

Grundy, E., Kravdal, O., 2010. Fertility history and cause-specific mortality: a register-based analysis of complete cohorts of Norwegian women and men. Soc. Sci. Med. 70, 18471857.

Henretta, J.C., 2007. Early childbearing, marital status, and women's health and mortality after age 50. J. Health Soc. Behav. 48, 254-266.

Hynes, K., Joyner, K., Peters, H.E., DeLeone, F.Y., 2008. The transition to early fatherhood: National estimates based in multiple surveys. Demogr. Res. 18, 337-376.

Kiernan, K.E., 1997. Becoming a young parent: a longitudinal study of associated factors. Br. J. Sociol. 48, 406-428.

Kravdal, O., Rindfuss, R.R., 2008. Changing relationship between education and fertility - study of women and men born 1940-64. American Sociological Review. 73, 854-873.

Laakintohallitus, 1969. Classificatio Morborotum Et Causarum Mortis. Tauti- Ja Kuolinsyyluokitus 1969. (Finnish Version of the International Classification of Diseases and Causes of Death, Eigth Revision). Laakintohallitus (National Board of Medicine), Helsinki.

Laakintohallitus, 1986. Tautiluokitus 1987. Osa 1 Systemaattinen Osa (Finnish Version of the International Classification of Diseases and Related Health Problems, Ninth Revision. Volume 1.). Laakintohallitus (National Board of Medicine), Helsinki.

Lahey, B.B., D'Onofrio, B.M., 2010. All in the Family: Comparing Siblings to Test Causal Hypotheses Regarding Environmental Influences on Behavior. Curr. Dir. Psychol. Sci. $19,319-323$. 
Lehti, V., Sourander, A., Sillanmaki, L., Helenius, H., Tamminen, T., Kumpulainen, K., Almqvist, F., 2012. Psychosocial factors associated with becoming a young father in Finland: a nationwide longitudinal study. BMC Public Health. 12, 560-2458-12-560.

Maggs, J.L., Patrick, M.E., Feinstein, L., 2008. Childhood and adolescent predictors of alcohol use and problems in adolescence and adulthood in the National Child Development Study. Addiction. 103 Suppl 1, 7-22.

Michael, R.T., Tuma, N.B., 1985. Entry into marriage and parenthood by young men and women: the influence of family background. Demography. 22, 515-544.

Nilsen, A.B., Waldenstrom, U., Rasmussen, S., Hjelmstedt, A., Schytt, E., 2013. Characteristics of first-time fathers of advanced age: a Norwegian population-based study. BMC Pregnancy Childbirth. 13, 29-2393-13-29.

Nisen, J., Martikainen, P., Silventoinen, K., Myrskyla, M., 2014. Age-specific fertility by educational level in the Finnish male cohort born 1940-1950. Demogr. Res. 31, 119-136.

Paavilainen, M., Bloigu, A., Hemminki, E., Gissler, M., Klemetti, R., 2016. Aging fatherhood in Finland - first-time fathers in Finland from 1987 to 2009. Scand. J. Public Health. 44, 423-430.

Pensola, T.H., Valkonen, T., 2002. Effect of parental social class, own education and social class on mortality among young men. Eur. J. Public Health. 12, 29-36.

Sjolund, S., Allebeck, P., Hemmingsson, T., 2011. Intelligence quotient (IQ) in adolescence and laterrisk of alcohol-related hospital admissions and deaths-37-year follow-up of Swedish conscripts. Addiction. 107, 89-97.

Sjolund, S., Hemmingsson, T., Allebeck, P., 2015. IQ and level of alcohol consumption-findings from a national survey of Swedish conscripts. Alcohol Clin. Exp. Res. 39, 548-555. 
Sondergaard, G., Osler, M., Andersen, A.M., Andersen, P.K., Dalton, S.O., Mortensen, L.H., 2015. Alcohol-related morbidity and mortality within siblings. Addiction. 110, 451-460.

Stakes, 1999. Tautiluokitus ICD-10. Systemaattinen Osa (Finnish Version of the International Statistical Classification of Diseases and Related Health Problems, Tenth Revision. Volume 1.). Stakes (National Research and Development Centre for Welfare and Health), Helsinki.

Statistics Finland, 2003. Suomen Virallinen Tilasto. Kuolemansyyt 2002 (Official Statistics of Finland: Causes of Death 2002). Statistics Finland, Helsinki.

Valkonen, T., Kauppinen, T., 2005. Märkä ja nuorena nukkuva sukupolvi? [Is the wet generation drinking itself to an early grave?]. In: A. Karisto (Ed.), Suuret Ikäluokat [Baby Boomers] Vastapaino, Jyväskylä, Finland, pp. 334-346.

Wolfe, J.D., 2009. Age at first birth and alcohol use. J Health Soc Behav. 50, 395-409. 
Table 1. Distribution of the study population and adjusted hazard ratios (HR) of the association between age at first birth and alcohol-related morbidity and mortality after age 35, cohort and intersibling analyses, men, Finland

\begin{tabular}{|c|c|c|c|c|c|c|c|c|}
\hline & \multirow{2}{*}{$\begin{array}{l}\text { Distribution } \\
\text { Cohort } \\
N(\%)\end{array}$} & \multirow{2}{*}{$\begin{array}{l}\text { Distribution } \\
\text { Siblings } \\
N(\%)\end{array}$} & \multicolumn{3}{|c|}{ Cohort analysis } & \multicolumn{3}{|c|}{ Inter-sibling analysis } \\
\hline & & & $H R$ & & $95 \% C I$ & $H R$ & & $95 \% C I$ \\
\hline \multicolumn{9}{|c|}{ Age at first birth } \\
\hline Under 20 & $1271(3 \%)$ & $605(3 \%)$ & 1.55 & $* * *$ & {$[1.33,1.81]$} & 1.36 & $* *$ & {$[1.09,1.69]$} \\
\hline $20-24$ & $14154(33 \%)$ & $7145(32 \%)$ & 1.23 & $* * *$ & {$[1.14,1.33]$} & 1.12 & $*$ & {$[1.00,1.25]$} \\
\hline 25-29 (ref.) & $12744(29 \%)$ & $6459(29 \%)$ & 1.00 & & & 1.00 & & \\
\hline $30-34$ & $4469(10 \%)$ & $2252(10 \%)$ & 0.80 & $* * *$ & {$[0.70,0.91]$} & 1.00 & & {$[0.84,1.19]$} \\
\hline $35-45$ & $2060(5 \%)$ & $1072(5 \%)$ & 0.53 & $* * *$ & {$[0.44,0.64]$} & 0.57 & $* * *$ & {$[0.43,0.75]$} \\
\hline No children & $8852(20 \%)$ & $4599(21 \%)$ & 1.33 & $* * *$ & {$[1.18,1.49]$} & 1.29 & $* *$ & {$[1.09,1.52]$} \\
\hline
\end{tabular}


Men's age at first birth and alcohol-related morbidity and mortality among siblings

Elina Einiö, Elina Hiltunen, Pekka Martikainen, Kaarina Korhonen

This material supplements, but does not replace, the peer-reviewed paper in Drug and Alcohol Dependence.

Table of Contents for Supplementary Material

Supplementary Table 1 Alcohol-related hospital diagnoses according to International Classification of Diseases (ICD), Finnish 8th, 9th, and 10th versions. 
Supplementary Table 1. Alcohol-related hospital diagnoses according to International Classification of Diseases (ICD), Finnish 8th, 9th, and 10th versions.

\begin{tabular}{|c|c|c|}
\hline ICD Revision & Code & Diagnosis \\
\hline \multirow[t]{8}{*}{ ICD-8 } & 26100 & Thiamine deficiency \\
\hline & 26200 & Niacin deficiency \\
\hline & 291 & Alcoholic psychosis \\
\hline & 303 & Alcoholism \\
\hline & 5710 & Alcoholic liver chirrosis \\
\hline & 577 & Diseases of pancreas \\
\hline & 980 & Alcohol intoxication \\
\hline & E860 & Accidental poisoning by alcohol \\
\hline \multirow[t]{13}{*}{ ICD-9 } & $2650 \mathrm{~A}$ & Alcoholic thiamine deficiency \\
\hline & 291 & Alcohol-induced mental disorders \\
\hline & 303 & Alcohol dependence syndrome \\
\hline & 3050 & Alcohol abuse \\
\hline & 3575 & Alcoholic polyneuropathy \\
\hline & 4255 & Alcoholic cardiomyopathy \\
\hline & 5307A & Mallory-Weiss syndrome \\
\hline & $5353 \mathrm{~A}$ & Alcoholic gastritis \\
\hline & $5710 A-5713 X$ & Chronic liver disease and chirrosis due to alcohol \\
\hline & $5770 \mathrm{D}-5770 \mathrm{~F}$ & Alcohol-induced acute pancreatitis \\
\hline & $5771 \mathrm{C}-5771 \mathrm{D}$ & Alcohol-induced chronic pancreatitis \\
\hline & 980 & Alcohol intoxication \\
\hline & E851 & Alcohol intoxication \\
\hline \multirow[t]{16}{*}{ ICD-10 } & F10 & Mental and behavioural disorders due to use of alcohol \\
\hline & G31.2 & Degeneration of nervous system due to alcohol \\
\hline & G40.51 & Epileptic seizure related to alcohol \\
\hline & G62.1 & Alcoholic polynerupathy \\
\hline & G72.1 & Alcoholic myopathy \\
\hline & I42.6 & Alcoholic cardiomyopathy \\
\hline & $\mathrm{K} 29.2$ & Alcoholic gastritis \\
\hline & K70 & Alcoholic liver disease \\
\hline & K85.2 & Alcohol-induced acute pancreatitis \\
\hline & K86.00 & Alcohol-induced chronic pancreatitis \\
\hline & T51 & Alcohol intoxication \\
\hline & $\mathrm{X} 45$ & Accidental poisoning by alcohol \\
\hline & E24.4 & Alcohol-induced pseudo-Cushing syndrome \\
\hline & E52 & Niacin deficiency \\
\hline & Y90 & Evidence of alcohol involvement determined by blood alcohol level \\
\hline & Y91 & Evidence of alcohol involvement determined by level of intoxication \\
\hline
\end{tabular}




\section{Author Disclosures}

Funding Source: This study was supported by the European Research Council Starting Grant (COSTPOST: 336475). PM was supported by the Academy of Finland. The views expressed here do not necessarily reflect the views of the Research Council or the Academy of Finland.

Role of Funding Source: Nothing declared. 